
cultures

Les cahiers de l'Acedle

9-1| 2012

Varia : plurilinguisme et transdisciplinarité

\title{
Editorial
}

\section{Marie-Françoise Narcy-Combes}

\section{(2) OpenEdition}

\section{Journals}

Édition électronique

URL : http://journals.openedition.org/rdlc/2486

DOI : $10.4000 /$ rdlc. 2486

ISSN : $1958-5772$

Éditeur

ACEDLE

Édition imprimée

Date de publication : 1 avril 2012

Référence électronique

Marie-Françoise Narcy-Combes, « Editorial », Recherches en didactique des langues et des cultures [En ligne], 9-1 | 2012, mis en ligne le 01 avril 2012, consulté le 25 septembre 2020. URL : http:// journals.openedition.org/rdlc/2486 ; DOI : https://doi.org/10.4000/rdlc.2486

\section{(c) (i) (2)}

Recherches en didactique des langues et des cultures is licensed under a Creative Commons AttributionNonCommercial-NoDerivatives 4.0 International License 


\section{Editorial}

Plurilinguisme et transdisciplinarité sont les deux mots clés qui traversent les articles de ce numéro. Ils reflètent les préoccupations des chercheurs en didactique des langues aujourd'hui. La transversalité apparait dans les ponts construits entre les apports des sciences sociales et la didactique des langues. Les travaux du Cadre Européen Commun de Référence pour les Langues ont permis la prise de conscience par des chercheurs, mais aussi des praticiens et des apprenants de plus en plus nombreux, que nous vivons dans une société plurilingue, contrairement à la représentation commune d'un monolinguisme dominant. Tous les articles évoquent la nécessité de relier recherche et pratique de terrain, et d'introduire les résultats des recherches menées en didactique des langues dans les cursus de formation des enseignants.

L'article de Frédéric Entermann et de Christine Cannard présente un intérêt particulier, dans la mesure où il illustre une collaboration qui apparaît aujourd'hui entre la didactique des langues et les disciplines connexes, ici la psychologie. Dans le cadre du plan réussite licence à l'université, les effets du tutorat, qui connaît un regain d'intérêt, sont mesurés et la corrélation entre la réussite des études universitaires et l'assiduité aux séances de tutorat (dont les bénéfices sociaux et cognitifs sont soulignés) a pu être établie, sans toutefois pouvoir déterminer s'il s'agissait d'une relation de cause à effet ou si le résultat était dû à l'attitude globale des étudiants, le tutorat étant alors intégré à une stratégie d'ensemble.

Nadine Normand-Marconnet utilise également les outils de la psychologie sociale, l'étude des représentations comme levier pour mettre en place les dispositifs susceptibles de les faire évoluer, et se place dans le cadre du Cecrl et du plurilinguisme. Les préoccupations dans se domaine débordent aujourd'hui le cadre de l'Europe, et son terrain d'étude concerne l'Iran. Elle s'interroge sur l'utilité du portfolio dans le cadre de l'autoévaluation des capacités langagières plurielles pour contribuer à la valorisation des répertoires plurilingues des individus. Elle est intimement liée, selon ses observations, aux représentations sociales que la culture éducative des apprenants de langues véhicule. La prise en compte de ces représentations est donc indispensable, faute de quoi des blocages sont à attendre. Cela passe par la nécessaire formation des enseignants, et des apprenants, au savoir apprendre tout au long de la vie.

Camille Vorger se penche sur le slam comme approche ludique et poétique de l'apprentissage langagier à l'école, en particulier en CLIN, et s'inscrit ainsi dans un mouvement particulièrement porteur aujourd'hui qui vise à associer les arts et le corps à l'acquisition de L2, et ne se limite plus aux structures spécifiques. Elle montre comment, en allant au plus 
près des préoccupations identitaires des élèves, on peut susciter leur intérêt, raviver leur créativité et favoriser leur intégration sociale.

Enfin Isabelle Puozzo Capron s'interroge sur les potentialités de la prise en compte et du développement du sentiment d'efficacité personnelle (SEP), un concept de psychologie, qu'elle transpose dans le domaine de l'apprentissage de L2 dans un contexte de bilinguisme, au Val d'Aoste. Dans une démarche de recherche-action, elle explore le potentiel du SEP pour l'apprentissage du français L2 par les tâches pour des élèves en cursus professionnalisant se destinant à l'hôtellerie. Il s'agit donc de langue de spécialité. Elle conclut à la nécessité d'accompagner les élèves sur le plan affectif, et non seulement sur le plan cognitif, de leur permettre d'entrer dans une démarche d'appropriation des contenus, et non de se limiter à les inciter à imiter et répéter, et donc de sensibiliser les enseignants à ces questions.

Marie-Françoise Narcy-Combes 